Ann. Génét. Sél. anım., I973, 5 (3), 4II-4I4.

NOTE

\title{
RECENT DEVELOPMENTS \\ IN RANDOM SAMPLE TESTS \\ FOR POULTRY IN THE UNITED KINGDOM ( $\left.{ }^{1}\right)$
}

\author{
P. A. C. THOMPSON and J. J. HOLMES
}

National Poultry Test Ltd.

Milford Test Ground Enton

Godalming, Surrey (Great Britain)

\section{SUMMARY}

This paper reports on the six random samples tests conducted by National Poultry Tests Ltd. and discusses the change of emphasis from a Breeder supported test where entry fees were charged and chicks were supplied free to a test which was entirely financed by the Company from its commercial activities and from the sale of a Technical Bulletin called Poultry Testing.

The paper reports on the way in which chicks for testing were obtained through third parties without the knowledge of the breeders, and discusses the advantages and disadvantages of obtaining chicks for testing by this method as opposed to the sampling of chicks in hatcheries from several different sources.

Also discussed are the difficulties in providing specific environments and management conditions for individual strains of bird in accordance with breeders recommendations and the importance of carrying out random sample tests under standard.conditions.

In the seven years since National Poultry Tests was formed six random sample egg production tests have been started. The first four have been completed and the fifth and sixth are currently in production. It is of interest to quickly look at the number of entries and number of different stocks which have been included in each of these tests. Table I lists the number of entries, the number of different commercial stocks in each test and these are divided into white and tinted layers and the brown egg layers. The right hand colum of table I shows the number of pullets housed per entry together with the replicate size and number.

Entry in the first four tests was on a voluntary basis. The poultry breeders supplied the hatching eggs or day old chicks and these were random sampled by independent officials of the Ministry of Agriculture, advisory service. The breeders in addition paid an entry fee. This entry fee went towards the cost of the testing operation.

(1) Cet article a été présenté à la réunion du groúpe de travail no 3 (sélection et testage) de la Fédération des Branches Européennes de la W.P.S.A., Nouzilly-Ploufragan, 6-1o septembre I $97 x$. 
TABLE I

National random sample egg Production tests

\begin{tabular}{c|c|c|c|c|c}
\hline \hline \multirow{2}{*}{$\begin{array}{c}\text { Test } \\
\text { number }\end{array}$} & $\begin{array}{c}\text { Number } \\
\text { of entries }\end{array}$ & $\begin{array}{c}\text { Number of different stocks } \\
\text { White } \\
+ \text { tinted }\end{array}$ & Brown & Total & $\begin{array}{c}\text { No. of bird } \\
\text { per entry }\end{array}$ \\
\hline & & & & & \\
\hline 1 & 32 & 14 & 6 & 20 & $4 \times 48=192$ \\
2 & 32 & 11 & 7 & 18 & $5 \times 48=240$ \\
3 & 21 & 9 & 2 & 11 & $6 \times 48=288$ \\
4 & 28 & 8 & 14 & 14 & $6 \times 48=288$ \\
5 & 22 & 12 & 10 & 22 & $6 \times 48=288$ \\
6 & 27 & 14 & 13 & 27 & $6 \times 48=288$ \\
\hline \hline
\end{tabular}

Opposition to testing amongst the poultry breeders in the United Kingdom rose to such a level in 1970 that it proved impossible to obtain samples of stocks on a voluntary basis for the fifth test. National Poultry Tests therefore decided that it would have to meet the cost of conducting the fifth test from its own income. We realized that we had a duty to the entire industry to provide independent facts and figures on poultry stocks and that this duty had to be met. You well know that the cost of running tests is very high and it puts an enormous burden on a small private company whose only source of income is derived from its farming activities. The fifth test was started by ordering day old chicks of thirty different commercial strains.

(a) In five cases the breeders concerned supplied the chicks free and promised donations equivalent to the old entry fees. In addition, they allowed independent officials to random sample the chicks in the hatcheries.

(b) We purchased samples of fourteen other commercial strains from the breeders and they also allowed independent officials to random sample the chicks.

(c) In the case of three of the commercial strains the breeders concerned were prepared to sell us the chicks but were not prepared to have them random sampled in the hatcheries.

(d) A further eight commercial strains were ordered but were found to be unobtainable at the time we required the chicks, for a variety of reasons.

This test therefore started with 22 different stocks, twelve white and tinted egg layers and ten brown egg layers which is more than we had had in any of the previous tests.

Early in I97I we decided that one way to raise financial support for our tests was to sell the results we produced. Thus Poultry Testing was launched in April 1971. This technical bulletin contains month by month test reports, information on various aspects of the tests, individual assessments of various stocks together with articles from leading authorities on technical subjects. Poultry Testing has been extremely well received in all quarters of the industry and although nowhere near large enough, the subscription list is growing at a very encouraging rate. Naturally, what has been written in Poultry Testing has not met with the approval of everybody concerned. This is to be expected when one is dealing with a subject such as the comparative performance of the products of commercial companies. Writing reports about the tests in a monthly bulletin provides an interesting challenge. The success of the tests depends upon the success of Poultry Testing. The readers of Poultry Testing must find the contents of value otherwise they will not subscribe to it. Thus one is writing the reports extracting information and putting it down in the form which is of most use to the commercial egg producer. One completely new aspect which 
we have included in Poultry Testing is the individual assessments of stocks. We have been extremely well pleased with the interest and assistance we have received from the poultry breeding companies in providing us with sources of information to help us in the work of making sound unbiased assessments of their stocks. We are in many cases dealing with truly international stocks and we make use of information from other countries. This can be from overseas test reports and also from survey data and individual farm results from different countries.

It could well be that we should publish much more information on reports from overseas in the interim period before we have a combined summary of European test reports.

The sixth series of tests was started in $197 \mathrm{I}$ and a completely new technique was used to obtain the day old chicks. Using a variety of methods we obtained the chicks through third parties without the knowledge of breeders concerned. We can tell you here and now that this method of obtaining stocks is very effective in that we were able to get twenty seven different stocks. Fourteen white and tinted egg layers and thirteen brown egg layers. Our maximum capacity is twenty-eight different stocks and if it had not been for a bad hatch in one instance and the fact that we did not want to wait for an extra two weeks to get replacement chicks we would have had all twenty-eight different stocks in this test. On the other hand making all the arrangements does create a vast amount of work. The ordering and collection of the chicks has to be coordinated so that they all arrive at the test and can be put into the brooder house within a few days of each other.

Another draw back to this method is that we were having to pay the full market price for all the chicks and did not obtain any entry fees. It is thus an expensive way of starting a test.

It would be obvious to you that tests started in this way can be seen by everybody in the industry to be completely independent. There can be no question of any collusion between the test authorities and the breeders in providing special samples of chicks for the test. However much we know that this does not go on, there are people in the industry who like to use this argument as a criticism of laying tests.

It is naive to think that nowadays the poultry breeding companies would go to the trouble of putting specially selected birds into public tests. These companies are selling stock in many countries throughout the world. In some countries the stock is sampled and put into official Governement tests and in others it is entered on a voluntary basis. If the results obtained in the different tests varied too much or if the results in tests were not typical of farm experiences then the credibility of that company would very soon decline. These companies have far too much at stake to take this sort of risk. When purchasing stock on the market there is always the chance of an inferior batch of chicks being bought. The breeder and hatchery organization will know of parent flocks that are not performing well, they will know of poor hatches. In general they will tell their customers that a particular hatch was of poor quality and will offer to supply chicks on an alternative date. The fact that this arises creates another element of chance when purchasing samples for a test. The breeder is much more likely to inform the test authorities that a particular hatch has not gone well if he knows that sampling officials will be calling to select chicks. If just a small batch of chicks are being sold to an individual customer there is a chance that the breeder would not inform him of this. This could add to the variation in results between test samples and is in itself an argument for having more tests and therefore more samples of each strain. This argument is very much in the breeders interests and is why it has been put forward by some of the breeding companies.

In the past we have conducted tests where two different layers diets were fed to all stocks. Half the replicates of each entry being fed on one diet and the other half being fed on the second diet. In the last completed we gave the entrants the opportunity to select which of two diets they wished their birds to be fed. We did this despite the fact that we believed that in many cases they were selecting the wrong diet. There are many arguments for and against having variable conditions under which to conduct tests. One can design factorial experiments but this would necessitate very large facilities for testing. One alternative put forward is that each stock 
should be subjected to the conditions of environment and management that are recommended by the breeder. In effect this means that if one was testing thirty different stocks, one would have to have probably at least I 20 separate poultry houses on the one site in order to be able to provide the conditions stipulated by the breeder and also to replicate these. The cost of building a unit of the size and altering its physical conditions before the start of each new test would be far beyond the means of a company of our size. It is possible that location tests could overcome this point and enable a wide range of stocks to be subjected to different conditions. One has to assess that altering the environment and management would change the ranking of the different stocks significantly. One can think of examples where some stocks kept in ten bird cages would produce disastrous results but if kept in three bird cages would perform moderately well.

Our main activities have been concerned with the testing of egg laying stocks. We have also conducted tests and experiments of other kinds on commission for individual companies and agencies. We have an open mind on the question of testing of other products. However we would maintain that the testing of stock, laying stock in particular is of greater importance than the testing of feed, equipment or other services.

Reçu pour publication en mars 1973.

\section{RÉSUMÉ \\ DÉVELOPPEMENTS RÉCENTS DES TESTS SUR ÉCHANTILLONS DE VOLAILLE PRIS AU HASARD DANS LE ROYAUME UNI}

Cet article est un rapport sur les six tests sur échantillons pris au hasard conduits par National Poultry Tests Ltd. Il discute l'évolution depuis un test supporté par les sélectionneurs, avec paiement de droits d'entrée et fourniture gratuite des poussins, jusqu'à un test entièrement financé par la Compagnie à partir de ses activités commerciales et de la vente d'un bulletin technique appelé Poultry Testing.

L'article expose la façon dont les poussins à tester ont été obtenus par la voie de tiers sans la connaissance des sélectionneurs, et discute les avantages et les inconvénients de cette méthode opposée à l'échantillonnage de poussins dans des couvoirs à partir de plusieurs sources différentes.

Sont également discutées les difficultés à apporter des environnements et conditions d'élevage spécifiques pour des lignées particulières d'oiseaux en accord avec les recommandations des sélectionneurs, et l'importance de conduire les tests dans des conditions standard. 